\title{
System Design of the Equipment Support Efficiency Evaluation Simulation System Based on HLA
}

\author{
Xiang Zhao ${ }^{1, a}$, Gang Chen ${ }^{2, b}$ and Lu Gao ${ }^{3, a}$ \\ ${ }^{1,3} 6^{\text {th }}$ department, Shijiazhuang Mechanical Engineering College, Hebei Province 050003, P. R. \\ China \\ ${ }^{2}$ HeBei Institutes of Communication, Shijiazhuang, Hebei Province 050003, P. R. China \\ azxcg2001@sina.com, b davidcg.yahoo.com
}

Keywords: Equipment support; simulation; efficiency evaluation; High Level Architecture

\begin{abstract}
HLA (High Level Architecture) is a distributed simulation framework; it has the advantage of portability, and reusable. This paper introduces HLA in the field of the equipment support efficiency evaluation simulation. It analyzes the basic principles of HLA and federal development process. The operating work and function are analyzed. The paper designed 9 modules for the equipment support efficiency evaluation simulation system base on HLA. The physical structure and logical structure are designed at last.
\end{abstract}

\section{Introduction}

The system design is the important stage in the developing process of software. The analysis and design of the equipment support efficiency evaluation simulation system described the system's functions and structures from some major users' angle, such as the decision personnel, equipment experts and support experts. It describes the design objective that the system should achieve and the assignment that the system needs to accomplish, namely system "what should be done". The design also presented the efficacy goal to achieve through the equipment support simulating process. It can suit many kinds of tactics levels equipment support situation and scenario. By way of setting up the input parameter that can change the simulation model. It can support equipment support commanding making and the equipment support action's simulation.

\section{Fundamental theory}

The basic concepts that HLA involving are the federation, and federate, object, and the operating supports environment (RTI, Run Time Infrastructure). The appointed subsystem such as the simulation system, support software and other related unit are called federation. They are organized for special aim and can realize cooperation action. Its running procedure is called confederation. Federation member is the simulation application and the other related applications which constituted the federation. The object is the established computer simulation model of the system in certain domain that wanted to be simulated. Federation member forms by the object. It's a soft-component and can be reused. The information exchange between federation members is realized by running the RTI service of the supporting environment. As shown in Fig.1, HLA can be divided into 3 layers at the component on the structure: the bottom level is the object, and the object formed federation member, and several federation members who can be operated mutually add RTI form the federation. By supporting of the general RTI, the spatial distribution federation member's (namely several of simulation applications) forms the distribution simulation system. It can accomplish the specially designated simulation assignment. 


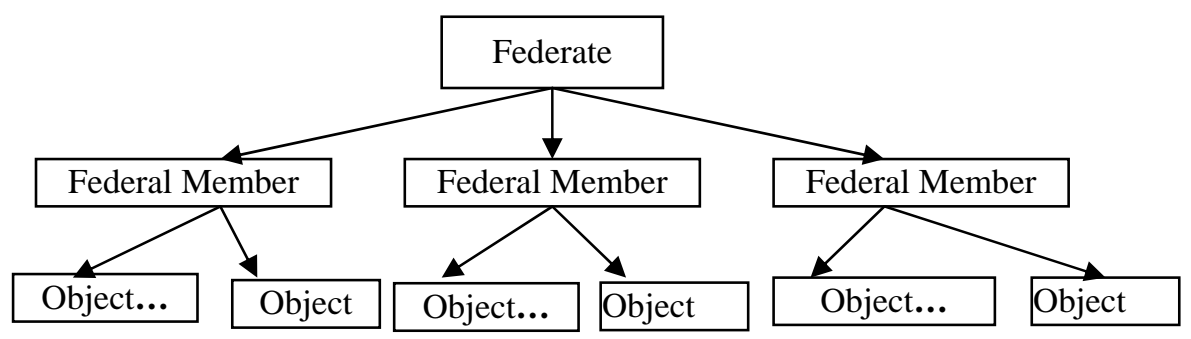

Figure 1 Simulation System Architecture based on HLA

\section{Demand analysis of the simulation system}

The system operating work description. The equipment support efficiency evaluation simulation procedure based on HLA is: Firstly, the battlefield is described as a complete dynamic course. The battlefield is decomposed by way of discrete method. The continuous operation time is divided to several stages. Each stage is cut to into several nodes. Next the battlefield force is divided to specially designated body that possesses fix determination and appointed function according to the time node. the support action is decomposed into basically actions or the incidents; Then according to the time order of the operational mission, the system simulated the equipment support organizes the activities such as commands etc in accordance with battlefield state. The system carries on simulation and gets the various trends information, draws out the equipment support efficiency evaluation related data at last. And the final efficiency synthesis evaluation result is gotten.

The functions requirement analysis. The efficiency evaluation simulation system should have the following functions:

(1) The function that simulating the equipment support process. It can suit many kinds of tactics levels equipment support situation and scenario. By way of setting up the input parameter that can change the simulation model. It can support equipment support commanding making and the equipment support action's simulation.

(2) The function that supporting the connection of RTI environment and equipment support model.

(3) The function that evaluating the equipment support efficiency. The simulation system can gathers and selects the simulation data at real time. It can carries on the statistical interpretation, and support in a minute stage at real time to equip maintenance support efficacy and assesses.

(4) The function that adding the personal intervention to the simulation. It includes the federation member's setting up, changing the time step length, adding the simulation incident and intervene the battle ending etc.

(5)The support developing the model. That is advantage to reuse of the federation member and systematic cooperation.

\section{System design of the simulation system}

system function module design. In order to satisfy the system function requirements, the equipment support efficiency simulation evaluation system's function is divided to 9 modules: data management module, simulation scenario creating module, mission control module, operation pattern control module, equipment damages simulation module , command object simulation module, execution substance simulation module, data acquisition module and the efficacy evaluation module. The work of each module and the effect design are as follows:

(1) data management module is managing all the simulation data in the system.

(2) simulation scenario creating module to create the simulation object that carry on the simulation trial module.

(3) the mission control model is the module control the initialization of the simulation system, and according to simulation purpose needs, selecting the corresponding scenario.

(4) the operation pattern control module is the module control the equipment support mission's carry out pattern. It can intervene and adjust to the course with command method. 
(5) the equipment damages simulation module is the module used to create the equipment damage incidents randomly.

(6) the command object simulation module is the equipment command post in the real support course. It put out the support commanding to the support action in equipping the maintenance support course.

(7) the execution object simulation module carries out the object support action. It chiefly is simulate the equipment unit's actions in different ways and time according to the equipment damage degree.

(8) the data acquisition module is collecting the equipment support efficiency evaluation data in different stages of simulation and store them for evaluating.

(9) the efficacy evaluation module is using the data which gathered in the simulation to calculate and gets the synthetically efficacy result.

system physical structure The equipment support efficiency evaluation simulation system is constituted by the simulation node, server node, simulation situation display node, data interface and computer networks. The physical structure of the equipment support efficiency evaluation simulation system is shown as Fig. 2.

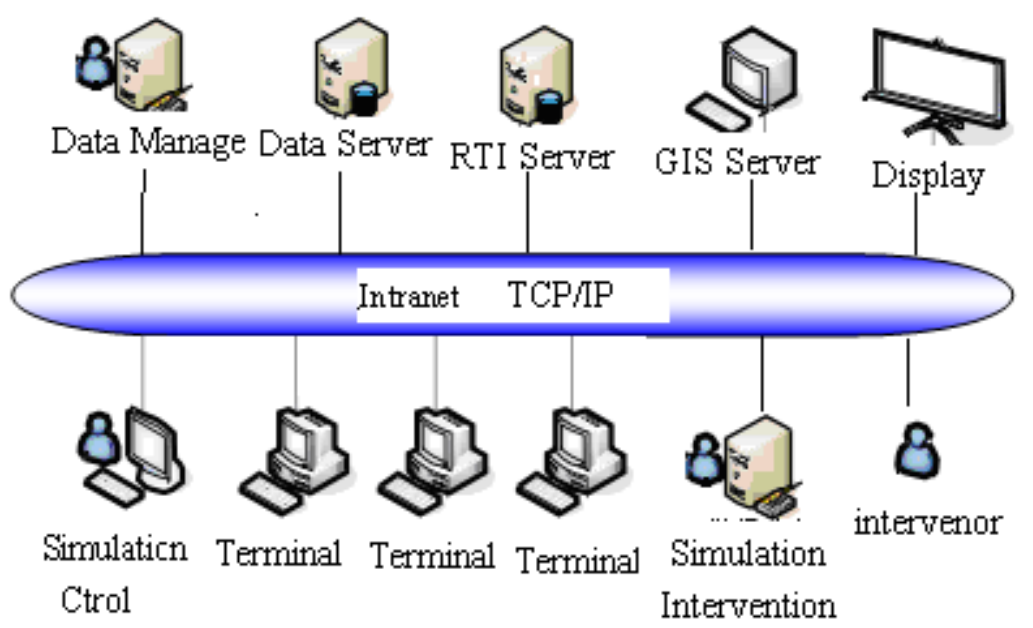

Figure 2 Physical structure of the equipment support efficiency simulation evaluation system based on HLA

- Simulation node module: The simulation node includes that simulation control, simulation terminal and simulation intervenes. The simulation control is the operating control center of the system. The simulation terminal is all sorts of model machine. They are running as the federation members. The simulation intervenes is set the circumstances parameters of the simulation course.

- Simulation situation display module: It can display the entire situation of the simulation process in real time.

- Data interface module: It can put-in and put-out the simulation data in several format.

- Computer network: It's a computer internet of the distribution federation members.

system logical structure According to the federation develop course based on HLA and system function modules, the simulation system is divides to 6 federation members: command object federation member, execution object federation member, the simulation control federation member, director federation member, simulation situation display federation member and efficacy evaluation federation member. These 6 federation members take the data management module as the foundation, and are ruing under the environment RTI. They cooperate mutually and formed the logical structure of the equipment support efficiency evaluation simulation system, which is shown in fig 3. 


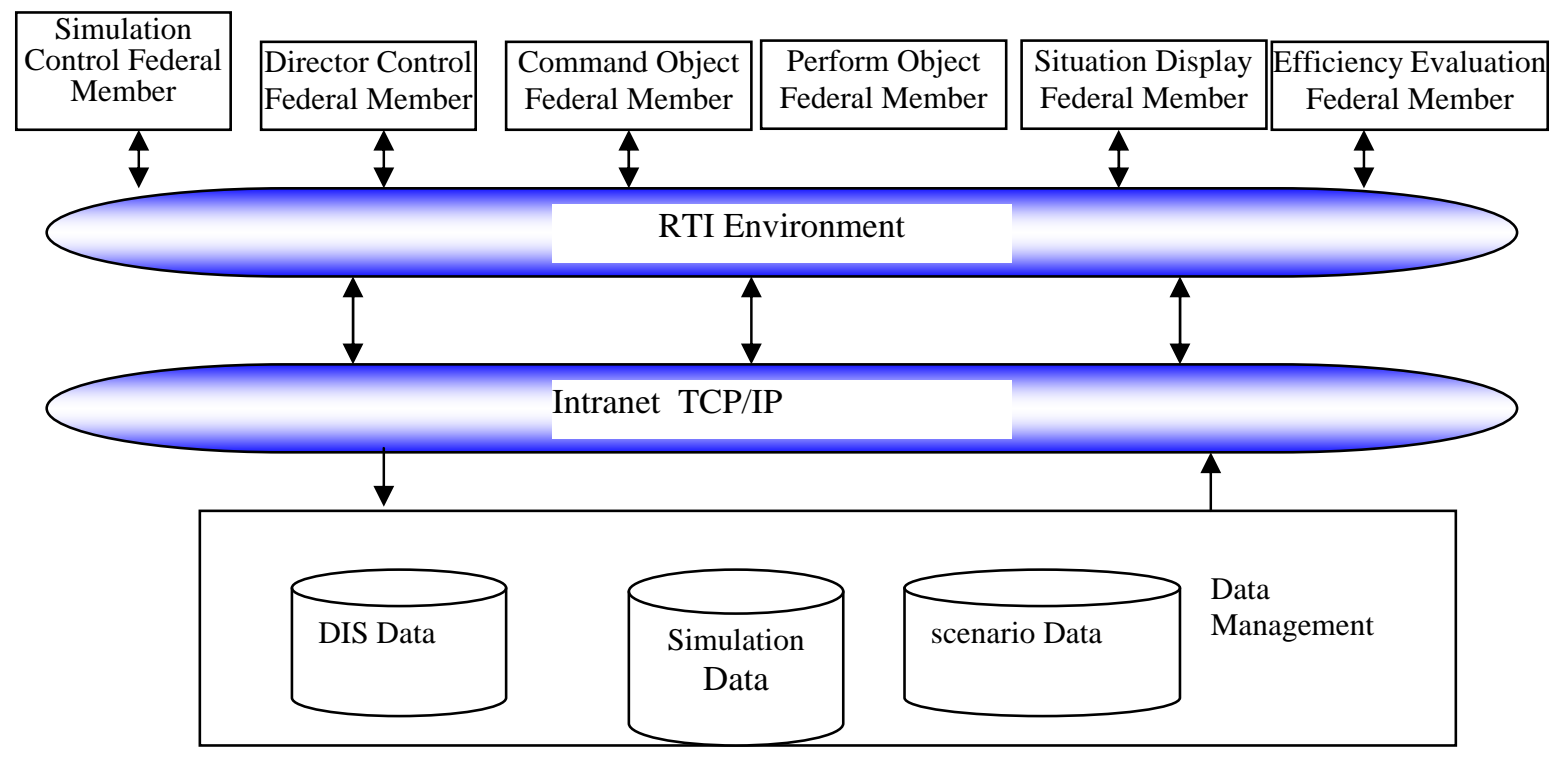

Figure 3 Logical structure of equipment support efficiency evaluation simulation system based on HLA

\section{Conclusions}

The paper introduced the basic concepts of HLA and the simulation system architecture based on HLA. Then, the demands analysis of the simuluation system is carried out. Based on the nesscessary demands, the phichal structure and logical structure of the equipment support efficiency evaluation simuluation system are proposed. The design of the simulation system is benefit for the succeeding development of the system.

\section{References}

[1] YUAN Ui-ping etral. Applying Open Source Name Engine for Building Visual Simulation Training System of Fire Fighting[C]// Asia Simulation Conference 2007, Communications in Computer and Information Science, Springer Berlin Heidelberg, 2007.

[2]YANG Jie, LI Chen, Study on Countermeasure Simulation System of Field Communication Network Based on HLA, Journal of System Simulation Vol 24 No. 3 Mar. (2012) pp, 128-131

[3]Jack Baker, Rich Joy, John Krause, Nelson Rodrigues, Joe Yomg. MSE -Transition from Voice to Data [C]// Military Communications 1993. MILCOM '93 Conference record, Communications on the Move' IEEE. USA: IEEE, 1993

[4] Zhen hua Hu, Evaluation for Equipment Technology Supporting Ability Based on Fuzzy Method, Ordnance Industry Automation, No.1 (2009), p.10

[5] Guang Kang and Ximin Jiang, Process Reengineering of Military Equipment Material Supply: Journal of Mechnical Engineering College, vol. 20, Shijiazhuang, (2008), pp. 13-14.

[6] Zhen hua Hu, Evaluation for Equipment Technology Supporting Ability Based on Fuzzy Method, Ordnance Industry Automation, No.1(2009), pp.10-13 